Results Twenty two infants met inclusion criteria. Over 90 measurements were obtained. TPN days ranged from 5 to 39 days. Seventeen infants $(77 \%)$ received TPN for less than 21 days of TPN. Their mean percent of body fat was $10.9 \%$, significantly lower than the $22 \%$ measured in those babies on $\geq 21$ days on TPN.

Conclusion In our population of VLBW, those who received TPN for longer than 3 weeks have a significant increase in body fat composition. This could result in increased risk for metabolic syndrome in early adulthood in this population. Our eagerness to avoid postnatal malnutrition could lead to an iatrogenic neonatal origin of adult disease. We are currently analyzing potential confounders and the TPN composition associated with these findings.

\section{COMPUTER AIDED NUTRITION - EFFECTS ON GROWTH IN PRETERM INFANTS GA $<32$ WEEKS}

doi:10.1136/archdischild-2012-302724.1401

1.2D Wackernagel, ${ }^{13} \mathrm{~A}$ Brückner, ${ }^{4} \mathrm{~F}$ Ahlsson. ${ }^{1}$ Department of Paediatrics, Mälarsjukhuset, Eskilstuna; 'Astrid Lindgen's Children Hospital, Karolinska University and Karolinska Institutet, Stockholm, Sweden; ${ }^{3}$ Department of Neonatology and Pediatric Intensive Care, Asklepios Childrenshospital St. Augustin, St. Augustin, Germany; ${ }^{4}$ Department of Women's and Children's Health, Uppsala University, Uppsala, Sweden

Background and Aims Preterm infants (PI) are often discharged from the NICU with suboptimal growth. It seems obvious that a commercial nutrition calculating program (NCP) could help to compute macro- and micro nutrients more easily. The aim of this intervention study was to determine whether a NCP could optimise the growth of PI.

Methods In 78 PI $(\mathrm{GA} \leq 32+0)$ cases grouped in 35 PI before (CG) and 43 after (IG) the implementation of the NCP Nutrium weight, length and head circumference at birth, day 28, GA 36 and discharge were compared.

Additionally daily intake of total fluid, energy, carbohydrate $(\mathrm{CH})$, aminoacids (AA), fatty acides (FA), Na, K, Ca, Mg, P, Fe, Zn and vitamine $\mathrm{A}, \mathrm{E}$ and $\mathrm{D}$ in postnatal weeks $1-7$ were recorded and compared.

\section{Results}

$\mathrm{AA}, \mathrm{CH}, \mathrm{Ca}, \mathrm{P}, \mathrm{Zn}$ intake was significantly increased. FA and total energy was marginally increased in week 1 . Vitamin A, E and $\mathrm{D}$ intake was optimised in IG and tended to be overdosed in CG (Recommendations based on Tsang/ESPGHAN).

Conclusion By using the NCP growth overall and especially length-growth was significantly optimised in PI $(\mathrm{GA} \leq 32+0)$ trough optimising intake of $\mathrm{CH}, \mathrm{AA}, \mathrm{Ca}, \mathrm{P}, \mathrm{Zn}$. In the IG it was more likely that Vitamins were dosed correctly.

\section{CHANGES ON PARENTERAL NUTRITION FOR VERY PRETERM BABIES DURING THE FIRST WEEK AND THEIR EFFECT ON GROWTH DURING ADMISSION}

doi:10.1136/archdischild-2012-302724.1402

II Iglesias-Platas, 'M Izquierdo-Renau, 'R del Río, ${ }^{2} \mathrm{P}$ González-Carretero, ${ }^{3} \mathrm{~N}$ Pociello, ${ }^{\prime} \mathrm{X}$ Krauel. ' Neonatal Unit, Hospital Sant Joan de Déu, Barcelona; ${ }^{2}$ Neonatal
Unit, Hospital Nuestra Señora de la Candelaria, Santa Cruz de Tenerife; ${ }^{3}$ Neonatal Unit, Hospital Arnau de Vilanova, Lleida, Spain

Current nutritional recommendations for very low birthweight infants (VLBWI) focus on avoiding catabolism and supporting growth. We aimed to assess the results of a change in the parenteral nutrition protocol for VLBWI in our unit on the nutritional support received by these patients during the first week of life and the growth rates achieved.

Patients Infants $<1500 \mathrm{~g}$ admitted to our unit one year before and one year after the change (periods I and II).

Method Revision of clinical charts and retrieval of data regarding nutritional intakes, growth and clinical outcomes.

Results 136 infants were studied (76 on period A and 60 on period B). There were no significant differences in baseline characteristics: gestational age (28.8 \pm 2.1 vs $29.0 \pm 2.0$ weeks), birthweight $(1.103 \pm 222$ vs $1.091 \pm 214 \mathrm{~g})$, gender distribution, perinatal characteristics and initial severity of illness. Parenteral nutrient supply was consistently higher throughout the first week in VLBWI in period II. There were no changes in enteral or total fluid supply.

The percentage of body weight loss was significantly lower in period $\mathrm{B}(11.3 \pm 4.9 \%$ vs $7.3 \pm 5.2 \%)$ and the recovery of birth weight was quicker ( 2 weeks vs 10 days, $p<0,0001$ ). The daily increase in weight was also significantly higher in the group with optimized nutrition, both from birth to day 14 of life and from day 14 to discharge.

Conclusions Extrauterine growth restriction is a prevalent complication of very preterm birth. Optimization of parenteral nutritional strategies in our neonatal unit had a positive effect in growth of this population during admission.

\section{DOES AMNIOTICFLUID PLAY A NUTRITIVE ROLE BEFORE BIRTH? A RETROSPECTIVE ANALYSIS OF NEWBORNINFANTS WITH UPPER AND LOWER GASTROINTESTINAL ATRESIA}

doi:10.1136/archdischild-2012-302724.1403

${ }^{1} \mathrm{H}$ Zillhardt, ${ }^{2} \mathrm{~J}$ Korczyk, ${ }^{2} \mathrm{~A}$ Heydweiller, ${ }^{3,4} \mathrm{H}$ Reutter, ${ }^{1} \mathrm{~A}$ Müller, ${ }^{1 P}$ Bartmann, ${ }^{1} \mathrm{~S}$ Bagci. ${ }^{1}$ Department of Neonatology, Children's Hospital; '2Department of Pediatric Surgery, University of Bonn; ${ }^{3}$ Department of Neonatology, Children's Hospital, Universiy of Bonn; ${ }^{4}$ Institute of Human Genetics, University of Bonn, Bonn, Germany

Introduction During pregnancy the fetus swallows and absorbs an increasing amount of amnioticfluid. It remains unclear whether a lack of absorption of amniotic fluid may result in low birth weight (BW). There are a few studies evaluating the significance of amniotic fluid on fetal growth and the their results are controversial. This study was carried out to evaluate the intrauterine nutritive role of amniotic fluid on fetal growth.

Method Neonates with atresia of gastrointestinal tract (GIT) during a period of 12 years were studied retrospectively. 29 from 100 patients were excluded from the statistical analysis because of VATER (VACTERL) association (8), chromosomal abnormalities (11) and congenital heart anomalies (10). BW and birth length (BL)

Abstract 1401 Table 1 Postnatal growth CG vs IG

\begin{tabular}{|c|c|c|c|c|c|c|c|c|c|}
\hline & group & $\begin{array}{c}\text { Birth } \\
(\text { mean } \pm S D)\end{array}$ & $\mathbf{p}$ & $\begin{array}{c}\text { Day } 28 \\
(\operatorname{mean} \pm S D)\end{array}$ & $\mathbf{p}$ & $\begin{array}{c}\text { GA36 } \\
(\text { mean } \pm S D)\end{array}$ & $\mathbf{p}$ & $\begin{array}{c}\text { Discharge } \\
\text { (mean } \pm \text { SD) }\end{array}$ & $\mathbf{p}$ \\
\hline Weight-SDS & $\begin{array}{l}\text { CG } \\
\text { IG }\end{array}$ & $\begin{array}{l}-1.4 \pm 1.7 \\
-1.0 \pm 1.5\end{array}$ & n.s. & $\begin{array}{l}-2.6 \pm 1.7 \\
-1.9 \pm 1.4\end{array}$ & 0.03 & $\begin{array}{l}-2.3 \pm 1.5 \\
-1.4 \pm 1.2\end{array}$ & $<0.05$ & $\begin{array}{l}-1.9 \pm 1.1 \\
-1.0 \pm 1.1\end{array}$ & $<0.05$ \\
\hline Lenth-SDS & $\begin{array}{l}\text { CG } \\
\text { IG }\end{array}$ & $\begin{array}{l}-1.8 \pm 2.0 \\
-1.2 \pm 1.9\end{array}$ & n.s. & $\begin{array}{l}-3.0 \pm 1.6 \\
-2.0 \pm 1.9\end{array}$ & 0.02 & $\begin{array}{l}-3.2 \pm 1.8 \\
-1.7 \pm 1.7\end{array}$ & $<0.05$ & $\begin{array}{l}-2.7 \pm 1.8 \\
-1.2 \pm 1.3\end{array}$ & $<0.05$ \\
\hline Headcircum.-SDS & $\begin{array}{l}\text { CG } \\
\text { IG }\end{array}$ & $\begin{array}{l}-0.4 \pm 1.3 \\
-0.5 \pm 1.1\end{array}$ & n.s. & $\begin{array}{l}-1.5 \pm 1.1 \\
-0.9 \pm 1.2\end{array}$ & 0.04 & $\begin{array}{l}-1.1 \pm 0.9 \\
-0.6 \pm 1.2\end{array}$ & 0.05 & $\begin{array}{l}-0.4 \pm 0.8 \\
+0.1 \pm 1.0\end{array}$ & 0.03 \\
\hline
\end{tabular}

